\title{
DENGUE UMA DOENÇA EMERGENTE NO ESTADO DO AMAZONAS
}

\author{
Cínthia Maria Teixeira Sampaio \\ Mestre do Programa de Pós-graduação em Geografia - UFAM \\ Universidade Federal do Amazonas \\ cinthia-sampaio2011@hotmail.com \\ Adoréa Rebello da Cunha Albuquerque \\ Professora Doutora do Programa de Pós-graduação em Geografia - UFAM \\ Universidade Federal do Amazonas \\ adorea27@yahoo.com.br
}

\begin{abstract}
RESUMO: A dengue é classificada como uma doença emergente já havia sido controlada e ressurge, o Município de São Gabriel da Cachoeira apresentou maior prevalência de doença $(700,16)$, Manaus $(657,15)$, Humaitá $(539,18)$. Compreender o processo do aumento da dengue no contexto das relações socioambientais. A metodologia sistematização de dados disponível no DATASUS, na FVS - AM e no Sistema de Informações de Agravos de Notificação - SINAN, utilizou-se a ferramenta QGIS 2.18. O estudo foi realizado através do número de internações hospitalares por dengue no período de 2007 a 2012, para o cálculo da prevalência utilizou-se o número de casos, divididos pela população de determinada área geográfica por cada 100.000 habitantes. Os resultados do aumento da dengue em decorrência do saneamento básico eficaz que não atende a demanda dos domicílios.
\end{abstract}

Palavras-chave: emergente, saneamento, ambiente.

\section{INTRODUÇÃO}

Descreve Luna (2002, p.231), postula-se que o conceito - doenças emergentes e reemergentes - emergem frente às limitações do paradigma hegemônico da teoria da transição Epidemiológica para explicar um novo quadro de morbimortalidade, especialmente à emergência da epidemia de HIV/AIDS nos países centrais. A Epidemiologia segue em paralelo à teoria da transição Demográfica, enfatiza-se que as doenças degenerativas substituiriam gradativamente às doenças emergentes e com o ressurgimento das epidemias, os países desenvolvidos e os países em desenvolvimento se inserem no processo saúde-doença.

Segundo a FVS - AM (Fundação de Vigilância Sanitária do Amazonas, 2016, p.1), a presença do Aedes aegypti na cidade de Manaus foi detectada, a partir de Novembro de 1996 e a do Aedes albopictus em Setembro de 1997. Portanto houve a migração do mosquito transmissor para outros Municípios do Estado do Amazonas. Em Fevereiro de 1998 foram registrados os primeiros casos autóctones de DENV-1 na Capital do Estado, dando início à epidemia. No entanto, a dengue se manifestou de forma endêmica com o registro de, pelo menos, quatro epidemias nos anos de 1998, 2001, 2011 e 2013. 


\section{MATERIAIS E MÉTODOS}

Compreender o processo do aumento das doenças no contexto das relações socioambientais. Como objetivos específicos: Apontar os dados demográficos do Instituto Brasileiro de Geografia e Estatística (IBGE), sobre a população urbana do Estado do Amazonas; Mencionar os dados da Secretaria de Estado de Meio Ambiente (SEMA), sobre os fatores ambientais.

Para os cálculos foi aplicada a taxa de prevalência de acordo com os estudos desenvolvidos pelo Wagner (1998), a taxa de prevalência é a soma dos números de casos da Dengue, divididos pela soma do total de indivíduos estudados.

Prevalência $=\underline{\text { Número de indivíduos afetados em um determinado momento } \times 100.000}$

Total de indivíduos estudados

\section{RESULTADOS E DISCUSSÕES}

De acordo com Dallari (1988, p.58), muito já se escreveu a respeito da conceituação da saúde durante a história da humanidade. Hipócrates, filósofo grego que viveu no século IV. a.C refere à influência da cidade e do tipo de vida de seus habitantes sobre a saúde e afirma que o médico não cometerá erros ao tratar as doenças, pois, envolve o ambiente de determinada localidade, precisa ser compreendido, e inserido no processo saúde-doença. Como mostra a (Fig. 1), a seguir.

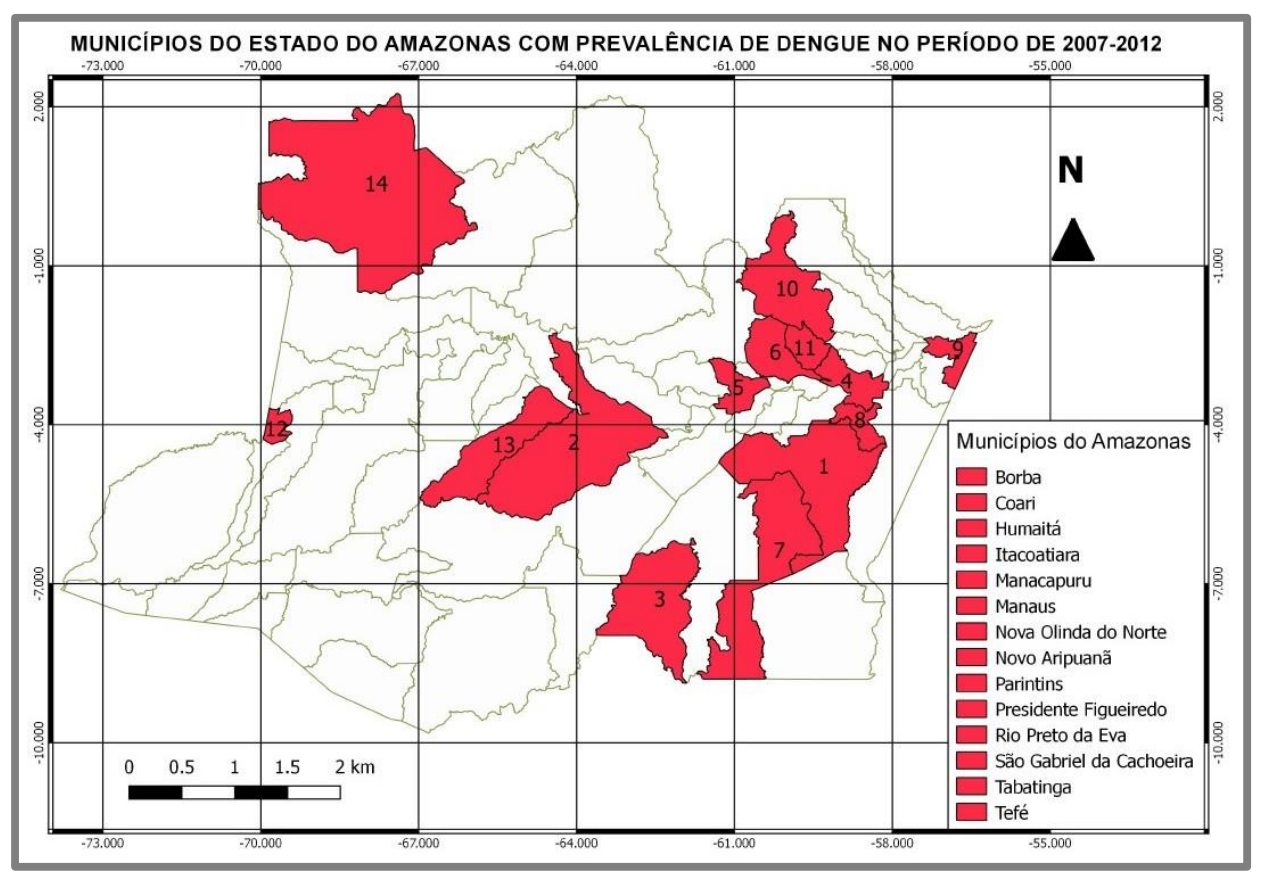

Figura 1 - Mapa dos Municípios do Estado do Amazonas com maiores incidência de Dengue. Fonte: FVS - AM, (2017). 
Segundo o (IBGE, 2017), a população do Estado do Amazonas corresponde a 3.483.985 milhões de habitantes, o equivalente a população total. Moram nas cidades 2.755.490, milhões de habitantes, o equivalente a $79 \%$, enquanto a rural o contingente populacional é de 728.495 milhões de habitantes, correspondendo a $21 \%$ do total. A grande maioria concentrada na capital do Estado, o que amplia ainda mais o desequilíbrio da distribuição da população (Censo, 2010).

Conforme o (IBGE, 2017), em relação ao saneamento básico no Estado do Amazonas, aproximadamente $24 \%$ da população urbana dispunha de abastecimento de água ${ }^{1}$ via rede geral, enquanto a população rural 19,3\% (Censo, 2010). Segundo o (DATASUS, 2018), a distribuição dos serviços de saneamento básico em 2010 no Estado do Amazonas na zona urbana, os serviços de coleta de lixo e limpeza foi de $84,19 \%$, a coleta por caçamba $9,75 \%$, a queima de lixo na propriedade $26,58 \%$, enterrado na propriedade $0,97 \%$, jogado em terreno baldio ou logradouro $2,79 \%$, jogado no rio $0,76 \%$ e outro destino 0,74 . Os Municípios com prevalência como a (Tabela 1), de dengue no Amazonas a maioria insere-se no espaço urbano, com saneamento básico eficaz.

Tabela 1 - Casos confirmados e taxas de prevalência de dengue no Estado do Amazonas, 2007 a 2012.

\begin{tabular}{lll}
\hline Municípios & $\begin{array}{l}\text { Casos } \\
\text { Confirmados }\end{array}$ & $\begin{array}{l}\text { Taxa de } \\
\text { prevalência } \\
\text { (em 100 mil } \\
\text { habitantes) }\end{array}$ \\
\hline Borba & 189 & $\begin{array}{c}90,41 \\
\text { Coari }\end{array}$ \\
Humaitá & 1.699 & 573,76 \\
Itacoatiara & 1.315 & 539,18 \\
Manacapuru & 1.462 & 27,88 \\
Manaus & 1.494 & 278,81 \\
Nova Olinda do Norte & 70.157 & 657,15 \\
Novo Aripuanã & 419 & 223,24 \\
Parintins & 565 & 465,81 \\
Presidente Figueiredo & 508 & 79,63 \\
Rio Preto da Eva & 108 & 66,90 \\
São Gabriel da Cachoeira & 60 & 37,83 \\
Tabatinga & 1.637 & 700,26 \\
Tefé & 593 & 196,83 \\
MU & 2.060 & 533,43
\end{tabular}

Fonte: DATASUS (2007 a 2012) - IBGE (Pop. Residente AM). Acesso 10/01/2018. Org.: Cinthia Sampaio, 2018.

\footnotetext{
${ }^{1}$ Indicadores de saneamento básico (PNAD). A cobertura ou proporção da população servida por rede de abastecimento de água: População residente em domicílios particulares permanentes servidos por rede geral de abastecimento de água, com ou sem canalização interna/ População total residente em domicílios particulares permanentes $\mathrm{X} 100$.
} 
Descrevem Souza (2010, p.19), é no ambiente urbano que o mosquito encontra o local propício para depositar seus ovos. Esse local é denominado de criadouro e, trata-se de qualquer recipiente que armazene ou possa a vir a armazenar água.

\section{CONCLUSÕES}

Os fatores sociais, o Estado do Amazonas, a ocupação urbana ultrapassa os limites da cidade é fragmentado e segregado, nos lugares privilegiados da cidade de média e alta renda, a estrutura urbana é mais adequada, as chuvas provocam problemas que afetam a mobilidade do trânsito, gerando algumas perdas econômicas, enquanto que nos lugares de baixa renda, os serviços de saneamento básico é eficaz, como: abastecimento de água, coleta de lixo e rede de esgoto, não atende a demanda de todos os domicílios.

\section{REFERÊNCIAS}

DALLARI, S. G. "The Right To Health." Revista de Saúde Pública, v.22, n.1, p. 57 63, 1988.

IBGE, Instituto Brasileiro De Geografia e Estatística. Estimativas da População dos Municípios Brasileiros 2010. Disponível em: <https://www.ibge.gov.br/> Acesso em: agosto de 2017.

LUNA, E. J. A. A emergência das doenças emergentes e as doenças infecciosas emergentes e reemergentes no Brasil. Rev. Bras. Epidemiol., v.5, n.3, 2002.

SOUZA, R. F. Associação entre fatores socioambientais e a presença do vetor da dengue: Uma Perspectiva da Geografia da Saúde na Cidade de Manaus. 2010. 105 f. Trabalho de Conclusão de Curso de Mestrado, Orientadora Albuquerque, Adoréa R. da C., (Dissertação) - Curso de Geografia, Universidade Federal do Amazonas, Manaus, AM, 2010.

WAGNER, B. M. Medindo a ocorrência da doença: prevalência ou incidência? In: Jornal de Pediatria, 74, p. 157-162, 1998.

FVS, Fundação em vigilância em saúde - AM, 2016. Boletim de Vigilância em Saúde. Situação epidemiológica da Dengue, Chikungunya e Zika Vírus no Estado do Amazonas, 2016, n.1, ano 5 - Março de 2016. Acesso em: agos. de 2017.

IBGE. 2018. Censo Demográfico 2010. Disponível em:< www.ibge.gov.br $>$ Acesso em: fev. de 2018. 
Brasil, Ministério da Saúde. 2018. DATASUS. Indicadores de Morbidade e Fatores de Risco - Taxa de Incidência da Dengue. Disponível em: <http://tabnet.datasus. gov.br/cgi/tabcgi.exeidb2018/d0203> Acesso em: fev. de 2018.

Recebido em 13/03/2018

Aceito em 30/05/2018 